\title{
The effect of a negative energy balance status on $\beta$-carotene availability in serum and follicular fluid of nonlactating dairy cows
}

\author{
J. De Bie, ${ }^{* 1}$ A. Langbeen, ${ }^{*}$ A. A. J. Verlaet, † F. Florizoone, $\ddagger$ I. Immig, $\ddagger$ N. Hermans, $†$ E. Fransen,§ \\ P. E. J. Bols, ${ }^{*}$ and J. L. M. R. Leroy* \\ ${ }^{*}$ Gamete Research Centre, Laboratory for Veterinary Physiology and Biochemistry, Department of Veterinary Sciences, University of Antwerp, \\ B-2610 Wilrijk, Belgium \\ †Laboratory of Nutrition and Functional Food Science, Department of Pharmaceutical Sciences, University of Antwerp, B-2610 Wilrijk, Belgium \\ łDSM Nutritional Products, $\mathrm{CH}-4303$ Kaiseraugst, Switzerland \\ $\S$ StatUa Center for Statistics, University of Antwerp, B-2610 Wilrijk, Belgium
}

\section{ABSTRACT}

Maternal metabolic pressure due to a cow's negative energy balance (NEB) has a negative effect on oocyte quality as a result of increased oxidative stress. In this study, we hypothesized that a NEB status may negatively affect the availability of $\beta$-carotene (bC, an antioxidant) in the micro-environment of the oocyte or follicular fluid (FF) and that daily bC supplementation can increase bC availability. We aimed to (1) determine the effect of a nutritionally induced NEB on bC concentrations in serum and $\mathrm{FF}$ as well as on the presence of bC metabolites, oxidative stress levels, and follicular growth in a nonlactating dairy cow model, and (2) investigate how this effect could be altered by dietary bC supplementation. Six multiparous nonlactating Holstein Friesian cows were subjected to 4 consecutive dietary treatments, $28 \mathrm{~d}$ each: (1) $1.2 \times$ maintenance (M) or positive energy balance (PEB) without bC supplement (PEB-bC), (2) $1.2 \times \mathrm{M}$ with daily supplement of 2,000 $\mathrm{mg}$ of bC comparable to the level of bC intake at grazing $(\mathrm{PEB}+\mathrm{bC}),(3) 0.6 \times \mathrm{M}$ with $2,000 \mathrm{mg}$ of $\mathrm{bC}(\mathrm{NEB}+\mathrm{bC})$, and (4) $0.6 \times \mathrm{M}$ (NEB-bC). At the end of each treatment, estrous cycles were synchronized and blood and FF of the largest follicle were sampled and analyzed for bC, retinol, $\alpha$-tocopherol, free fatty acids, estradiol, and progesterone. Serum cholesterol, triglycerides, urea, insulin growth factor 1 , growth hormone, total antioxidant status (TAS), and red blood cell glutathione (GSH) concentrations were determined as well. All cows lost body weight during both energy restriction periods and showed increased serum free fatty acid concentrations, illustrating a NEB. A dietary induced NEB reduced FF bC, but not plasma $\mathrm{bC}$ or plasma and FF retinol concentrations. However, $\mathrm{bC}$ and retinol concentrations drastically increased in

Received January 8, 2016

Accepted March 10, 2016.

${ }^{1}$ Corresponding author: Jessie.debie@uantwerpen.be both fluid compartments after bC supplementation. Follicular diameter was increased in supplemented PEB cows. Energy restriction reduced the TAS and red blood cell GSH, whereas daily bC supplementation could restore GSH concentrations, but not the TAS, to levels present in healthy PEB cows. In conclusion, daily bC supplementation can substantially improve bC and retinol availability in the oocyte's micro-environment, irrespective of the energy balance, which may affect follicular development and oocyte quality in the presence of maternal metabolic stress. This knowledge can be of importance to optimize nutritional strategies in the dairy industry to feed for optimal oocyte quality and fertility.

Key words: dairy cow, fertility, negative energy balance, $\beta$-carotene, follicular fluid

\section{INTRODUCTION}

The dairy industry has evolved drastically: due to decades of selection toward milk production, the modern high-yielding dairy cow produces up to $10,000 \mathrm{~L}$ of milk per lactation (CRV, 2012). This, together with a reduced appetite postpartum and thus reduction in DMI, contributes to the inability of a cow to compensate for the high loss of glucose through the udder. As a result, cows enter a period of negative energy balance (NEB) and increased metabolic stress that is associated with reduced fertility (Rukkwamsuk et al., 1999; Butler, 2003; Wathes et al., 2003; Drackley et al., 2005; Leroy et al., 2011). One important identified factor in the pathogenesis of subfertility during this period is the negative effect of metabolic stress due to the NEB (Bernabucci et al., 2005) on ovarian follicle and oocyte development (Beam and Butler, 1997; Kendrick et al., 1999; Dupont et al., 2014). During this NEB, upregulated lipolysis of fat stores results in increased serum free fatty acid (FFA) concentrations (Drackley et al., 2001). These FFA are reflected in the follicular fluid (FF; Leroy et al., 2004a), in which the oocyte matures, jeopardizing 
granulosa cell viability (Vanholder et al., 2005), oocyte developmental competence and subsequent embryo quality, and thus dairy cow fertility (Leroy et al., 2005; Van Hoeck et al., 2011, 2012). Gene expression analysis and functional assays of FFA-exposed oocytes, cumulus cells, and subsequent blastocysts pointed out the importance of pathways related to oxidative metabolism, redox status, and oxidative stress (OS; Van Hoeck et al., 2013).

The above described subfertility syndrome in modern dairying is a multifactorial problem in which not only genetics and management, but also nutrition, play a crucial role (Chagas et al., 2007). Substantial research has been performed on altering dairy cow nutrition to improve fertility (Santos et al., 2010; Leroy et al., 2014). In recent years, optimum vitamin nutrition in the dairy industry has gained more attention (for overview, see Calsamiglia and Rodríguez, 2012). Interest has been rising on dietary $\beta$-carotene (bC; provitamin A, precursor of retinol) because of its strong antioxidative properties and promising results on pregnancy rates in dairy cows following daily supplementation (Iwańska and Strusinska, 1997; Arechiga et al., 1998; Gossen and Hoedemaker, 2005; de Ondarza and Engstrom, 2009). Nowadays, dairy cows are more frequently housed under zero-grazing conditions in which cows are fed with conserved forages containing substantially lower bC levels than fresh grass (Chaveau-Duriot et al., 2005), emphasizing the rise of interest in the use of $\mathrm{bC}$ in the dairy industry. Considering the fact that OS is one of the main pathways by which elevated FFA affect bovine oocytes and embryos (Van Hoeck et al., 2013), bC might be a promising solution to ameliorate oocyte and embryo quality and thus dairy cow fertility. In contrast to the lack of in vitro research on bC and its effects on oocyte and embryo development, substantial in vivo research has been done investigating the effect of bC on dairy cow fertility. However, conflicting results about the actual effects of bC on dairy cow reproduction exist possibly due to (1) evaluation of reproductive performance by biased parameters as extensively reviewed by LeBlanc (2010); (2) the presence of bC in the control ration (Folman et al., 1983); (3) differences in the composition of the ration (Warner et al., 1970; Blomhoff et al., 1991; Yeum et al., 2000); (4) discrepancies in bC metabolism between different cow breeds (Bremel et al., 1982); and (5) differences in milk fat production and thus possible loss of fat-soluble bC through milk. Additionally, the most recent recommendations on bC supplementation in the dairy industry date from 2001 (NRC), and it is unlikely that these specific vitamin needs are still applicable to modern dairy cows (Barroeta et al., 2012). This stresses the need for more in- depth information on bC supplementation and its effect on dairy cow reproduction.

Extensive research on the addition of antioxidants with the aim to optimize in vitro oocyte maturation and embryo culture media (reviewed in Premkumar and Agarwal, 2012) or to reduce reactive oxygen species in follicle cells, oocytes, and embryos shows beneficial effects (Pascoe et al., 1987; Olson and Seidel, 2000; Natarajan et al., 2010; Tao et al., 2010; Lin et al., 2013). It has been assumed that bC present in the FF can protect follicle cells and oocytes from reactive oxygen species (ROS)-mediated cytotoxicity (Ikeda et al., 2005). Moreover, in vitro research has shown that fatty acid-induced toxicity at the embryo level can be counteracted by the addition of antioxidants to the culture medium such as $\alpha$-tocopherol (vitamin E; Rooke et al., 2012). Consequently, the antioxidant capacity of bC can possibly reduce the OS in the oocyte as a consequence of a NEB state. However, little is known about the availability of $\mathrm{bC}$ in the FF, the microenvironment of the maturating oocyte, and how oral supplementation can affect this. Furthermore, it can be hypothesized that the status of a NEB negatively affects serum and FF bC concentrations due to a higher systemic use (Sangsritavong et al., 2002). The NEB is primarily determined by a reduced DMI in the cow (Santos et al., 2010), rather than the increased energy loss through milk production. However, the significant rise in milk production can corroborate to the bC loss during NEB through milk. Consequently, a cow's milk production level and the concomitant metabolic stress status postpartum might complicate the understanding of how bC can reach the FF (Akar and Gazioglu, 2006; Calderón et al., 2007). A first important step that can contribute to clarify the effect of these confounders on the presence of $\mathrm{bC}$ in serum and $\mathrm{FF}$ is to unravel the underlying mechanisms in a fully controlled nonlactating dietary induced NEB cow model. As such we will investigate the effect of underfeeding and the subsequent NEB on the bC availability in blood and FF. Therefore, we aimed to (1) determine the effect of a nutritionally induced NEB on bC concentrations in serum and $\mathrm{FF}$ as well as on the presence of bC metabolites, OS levels, and follicular growth in a nonlactating dairy cow model, and (2) investigate how this effect could be altered by dietary bC supplementation.

\section{MATERIALS AND METHODS}

All chemicals were obtained from Sigma-Aldrich (Bornem, Belgium) unless specified otherwise and all compounds and reagents used for HPLC were of analytical grade. Results are shown as means \pm SEM. 
Table 1. Diet composition calculated for nonlactating Holstein Friesian cows with average BW of $600 \mathrm{~kg}$

\begin{tabular}{lcc}
\hline Item & $\begin{array}{c}\mathrm{PEB}^{1} \\
(1.2 \times \mathrm{M})\end{array}$ & $\begin{array}{c}\mathrm{NEB}^{1} \\
(0.6 \times \mathrm{M})\end{array}$ \\
\hline Hay of average quality $^{2}(\mathrm{~kg}$ of DM) & 7.26 & 3.63 \\
Chopped straw $^{3}(\mathrm{~kg}$ of DM) & 1.90 & 0.95 \\
Concentrate Bovimix 15\% protein $^{4}(\mathrm{~kg}$ of DM) & 1.55 & 0.77 \\
Net energy (mJ/d) & \pm 41.4 & \pm 20.7 \\
\hline${ }^{1} \mathrm{PEB}=$ positive energy balance; NEB = negative energy balance; M = maintenance. & \\
${ }^{2}$ Hay contains 3,419 kJ of net energy per kg of DM. & \\
${ }^{3}$ Straw contains 3,043 kJ of net energy per kg of DM. & \\
${ }^{4}$ Concentrates contain 15\% CP, 4\% crude fat, 7.5\% crude ash, and 14.5\% crude cellulose on a DM basis and \\
6,964 kJ net energy per kg of DM (Quartes, Roeselaere, Belgium).
\end{tabular}

\section{Animals and In Vivo Experimental Design}

Six healthy multiparous nonlactating dairy cows $(3.8 \pm 0.2$ yr old; $545 \pm 25 \mathrm{~kg})$ were used for this experiment. All procedures were performed at the department of Veterinary Sciences, University of Antwerp. The experimental protocol was approved by the Ethical Committee on Animal Experimentation (ECD 2013-15, University of Antwerp).

The experimental design of this study is shown in Figure 1. After a 6 -wk acclimatization period before the start of the experiment, in which the animals were fed ad libitum (hay and concentrates), cows were subjected to 4 consecutive dietary treatments of $28 \mathrm{~d}$ each: (1) $1.2 \times$ maintenance $(\mathbf{M})$ or positive energy balance (PEB) without bC supplement (PEB-bC), (2) $1.2 \times \mathrm{M}$ with daily supplement of $2,000 \mathrm{mg}$ of $\mathrm{bC}$ comparable to the level of $\mathrm{bC}$ intake at grazing
(Kawashima et al., 2010; $20 \mathrm{~g}$ of Rovimix $\beta$-carotene $10 \%$, DSM Nutritional Products, Kaiseraugst, Switzerland; PEB+bC), (3) $0.6 \times \mathrm{M}$ with 2,000 $\mathrm{mg}$ of $\mathrm{bC}(\mathbf{N E B}+\mathbf{b C})$, and (4) $0.6 \times \mathrm{M}(\mathbf{N E B}-\mathbf{b C})$. Due to the relative long half-life of bC (approximately $5 \mathrm{~d}$; Dimitrov et al., 1986; Schwedhelm et al., 2003), a 6-wk wash-out period (ad libitum feed intake) was included after the third treatment to reduce blood bC concentrations to basal levels. During the experimental period, cows were fed twice daily. Cows were individually tied up in a stable next to each other to have full control of their proper energy intake. Five times a week, during half a day, cows had a paddock at their disposal with no grass available. Rations were calculated per BW and consisted of average quality hay, chopped straw, and concentrates $(15 \% \mathrm{CP}, 4 \%$ crude fat, $7.5 \%$ crude ash, and $14.5 \%$ crude cellulose; Table 1). Body weight was monitored weekly.

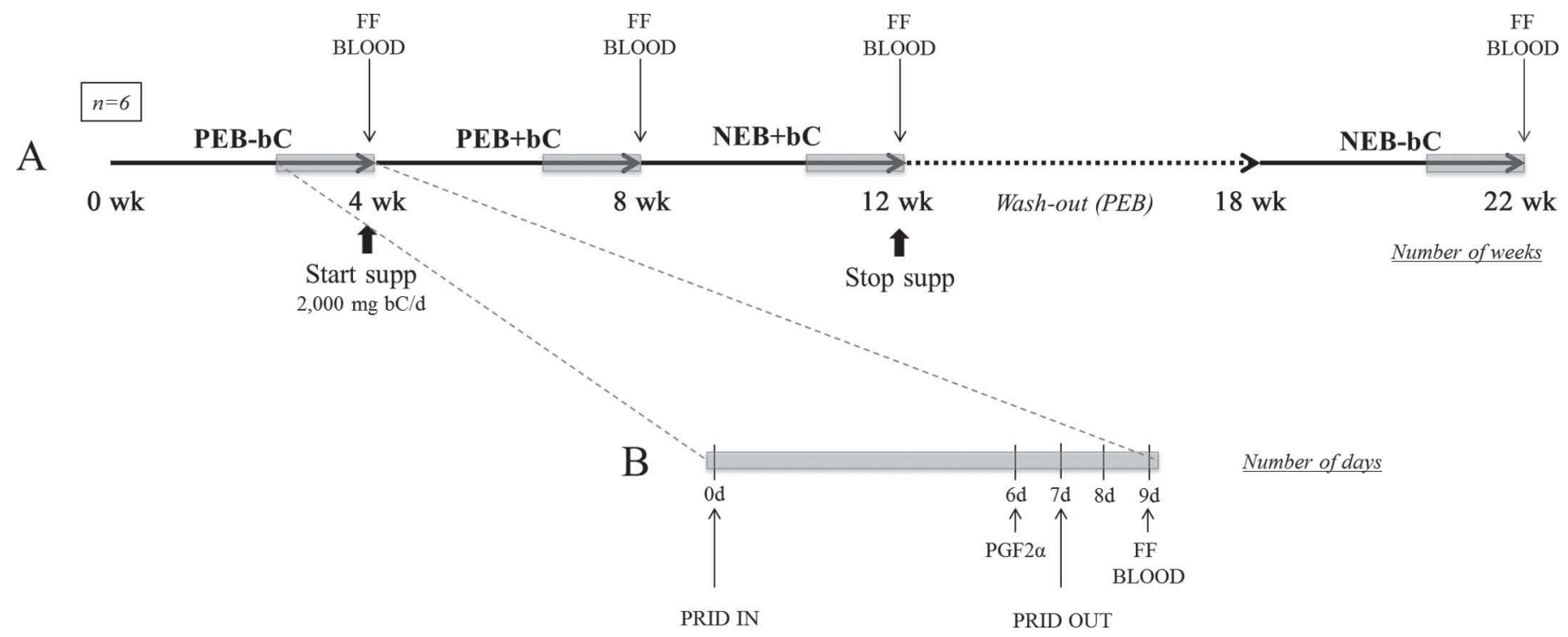

Figure 1. In vivo experimental design. (A) Presentation of the 4 consecutive dietary treatments including a 6-wk wash-out period inserted before the last treatment. (B) Presentation of the synchronization protocol during the last $9 \mathrm{~d}$ of each dietary treatment. PEB $=$ positive energy balance; NEB = negative energy balance; $\mathrm{FF}=$ follicular fluid; supp = supplementation; bC = $\beta$-carotene $(2,000 \mathrm{mg} / \mathrm{d}$ or $20 \mathrm{~g}$ of Rovimix $\beta$-carotene 10\%, DSM Nutritional Products, Kaiseraugst, Switzerland); PRID = progesterone intravaginal device. 
To synchronize the moment of ovulation in all cows, a progesterone-releasing intravaginal device (PRID; $1.55 \mathrm{~g}$ of progesterone, CEVA, Brussels, Belgium) was used. During the last $9 \mathrm{~d}$ of each dietary period, cows were synchronized by placing a PRID for $7 \mathrm{~d}$ and a $\mathrm{PGF}_{2 \alpha}$ injection (Dinolytic, Pfizer, Elsene, Belgium) on d 6 after PRID insertion (Figure 1B). Together with FF collection $36 \mathrm{~h}$ after PRID removal, blood was sampled.

\section{Sampling of FF and Blood}

At the end of each dietary period, $36 \mathrm{~h}$ after PRID removal, FF was collected (Figure 1). Dominant follicles $(>8 \mathrm{~mm})$ were punctured because they contain all nutrients necessary for the oocyte to be ready to ovulate. Follicular fluid was sampled using the ultrasound-guided transvaginal oocyte pick-up method as described by Leroy et al. (2004b). Briefly, the rectum was emptied and the external genitalia were carefully disinfected. All cows received an epidural injection (5 $\mathrm{mL}$ of Procain $\mathrm{HCl}$ 4\%, VMD, Arendonk, Belgium) to prevent them from straining. An ultrasound device with a 7.5-MHz electronic sector transducer (Pie Medical Imaging, Maastricht, the Netherlands) and needle guidance system was inserted into the vagina. Through rectal manipulation, both ovaries were visualized and the diameter of the dominant follicle was recorded. The dominant follicle was positioned on the biopsy line, punctured, and $\mathrm{FF}$ was aspirated by means of a $5-\mathrm{mL}$ syringe connected to the needle by a stainless steel connector to a thin silicone tube (Bols et al., 1995). Samples contaminated with blood were omitted from the study. Immediately after aspiration, the collected FF samples were cooled on melting ice until further processing $\left(4^{\circ} \mathrm{C}\right)$. Within $3 \mathrm{~h}, \mathrm{FF}$ was centrifuged for $10 \min \left(10,000 \times g, 4^{\circ} \mathrm{C}\right.$; Leroy et al., 2004b) and supernatant was frozen $\left(-80^{\circ} \mathrm{C}\right)$ until further analysis on retinol, $\alpha$-tocopherol (aT), bC, FFA, estrogen (E2), and progesterone $(\mathbf{P} 4)$ concentrations.

Plasma and serum samples were collected from each cow on the day of FF sampling. Plasma was sampled from a jugular vein in EDTA tubes (Vacuette, $9 \mathrm{~mL}$ of K2E, Greiner Bio-One, Wemmel, Belgium) and serum in clot activating tubes (Vacuette, $9 \mathrm{~mL}$ of Serum Clot Activator). After the EDTA blood tubes were gently mixed, they were immediately put on ice until further processing. The coagulated blood samples were kept at room temperature for a minimum of $1 \mathrm{~h}$. Within $3 \mathrm{~h}$, clot activating tubes were centrifuged for $30 \mathrm{~min}$ $(1,400 \times g)$ and EDTA tubes were centrifuged for 10 min $\left(1,000 \times g ; 4^{\circ} \mathrm{C}\right)$ after which plasma, red blood cells (RBC), and serum were collected. Then, $50 \%$ (vol/vol) $50 \mathrm{~m} M$ phosphate-buffer $\left(20 \mathrm{mM} \mathrm{NaH} \mathrm{PO}_{4}, 30 \mathrm{~m} M\right.$ $\mathrm{Na}_{2} \mathrm{HPO}_{4}$, Carl Roth, Karlsruhe, Germany) with $2 \mathrm{mM}$
EDTA was added to all RBC samples. All samples were stored at $-80^{\circ} \mathrm{C}$ until they were analyzed for plasma retinol, aT and bC concentrations, $\mathrm{RBC}$ glutathione (GSH) concentrations, and serum biochemical parameters [total antioxidative status (TAS), FFA, triglycerides (TG), total cholesterol (CH), urea, IGF-1, growth hormone (GH), E2, and P4].

\section{Biochemical Analyses}

Within and between coefficients of variation are indicated between parentheses as percentages. Urea $(1.7,2.2)$, TG $(1.3,2.3)$, and total $\mathrm{CH}(1.1,1.4)$ were enzymatically determined with photometric analysis (c16000 analyzers, Abbott Diagnostics, Santa Clara, CA). Estrogen $(2.1,2.2)$ and P4 $(2.0,3.8)$ were analyzed using a chemiluminescent particle immunoassay (i2000 analyzers, Abbott Diagnostics). Radioimmunoassay kits were used to measure IGF-1 $(9.8,10.4)$ and GH $(4.4,8.9)$ concentrations (Diasource, Louvain-LaNeuve, Belgium). Free fatty acids $(2.5,4.9)$ and TAS (9.0, between run variation) were measured photometrically using RX Daytona (Randox Laboratories, Crumlin, Ireland).

\section{Glutathione Analyses}

Within 2 wk after collection, RBC samples containing $50 \%$ phosphate/EDTA were thawed, immediately centrifuged $\left(5,000 \times g, 10 \mathrm{~min}, 4^{\circ} \mathrm{C}\right)$, and supernatant was transferred to centrifuge filter tubes (VWR, Leuven, Belgium) after which they were centrifuged again $\left(14,000 \times g, 20 \mathrm{~min}, 4^{\circ} \mathrm{C}\right)$. The $\mathrm{RBC}$ filtrate was diluted 1/320 with mobile phase A (3\% (vol/vol) methanol (Fisher Scientific, Aalst, Belgium); $97 \%$ (vol/ vol) HPLC-grade water; $25 \mathrm{mM} \mathrm{NaH} \mathrm{PO}_{4} ; 1.4 \mathrm{mM}$ octanesulfonic acid; $\mathrm{pH} 2.7$ ), and $5 \%$ (vol/vol) $\mathrm{H}_{3} \mathrm{PO}_{4}$ was added. A negative control (phosphate/EDTA buffer) was included with each analytical procedure. Samples $(100 \mu \mathrm{L})$ were injected by a Gilson 234 autosampler with 832 sample cooler at $7^{\circ} \mathrm{C}$ and analyzed on a Gilson 321-H1 HPLC system (Gilson Inc., Den Haag, the Netherlands) with ESA-5600A CoulArray 8-channel electrochemical detector with Thermal Organizer (Thermo Scientific, Aalst, Belgium). Mobile phase B consisted of $50 \%$ (vol/vol) methanol (Fisher Scientific); $50 \%$ (vol/vol) HPLC-grade water; $25 \mathrm{mM} \mathrm{NaH}{ }_{2} \mathrm{PO}_{4}$, and $1.4 \mathrm{mM}$ octanesulfonic acid $(\mathrm{pH} 2.7)$. The HPLC flow rate was set at $0.7 \mathrm{~mL} / \mathrm{min}$ and the gradient profile consisted of a 25-min linear gradient from 0 to $50 \%$ mobile phase B, a 5-min linear gradient from 50 to $100 \%$ mobile phase $\mathrm{B}$, and $5 \mathrm{~min}$ isocratic at $100 \%$ mobile phase B before returning to initial conditions in 5 min ending with 5 min isocratic at $0 \%$ mobile phase 
B. Cell potentials were set at 500, 580, $660,740,820$, 900,980 , and $0 \mathrm{mV}$ versus the palladium reference. A C18 reversed phase column $(4 \times 250 \mathrm{~mm} ; 5 \mu \mathrm{m}$; Merck, Darmstadt, Germany) was used.

\section{Vitamin Analyses}

Plasma samples were analyzed on fat-soluble vitamins as described by Hermans et al. (2005) with minor modifications, using a validated HPLC 8-coulometric method. Briefly, fat-soluble vitamins were extracted from plasma and standards by means of n-hexane (Fisher Scientific). A negative control was included with each analytical procedure. Following centrifugation $\left(4,000 \times g, 10 \mathrm{~min}, 4^{\circ} \mathrm{C}\right)$, supernatant was collected and this extraction procedure was repeated twice. All supernatant was evaporated by vacuum centrifugation and the residue was redissolved in ethanol and analyzed on a Gilson 321-H1 HPLC system with ESA-5600A CoulArray 8-channel electrochemical detector with Thermal Organizer. During the analysis, samples were cooled at $7^{\circ} \mathrm{C}$. Mobile phase A consisted of methanol (Fisher Scientific): HPLC grade water: $1 M$ ammonium acetate (Merck; 90:8:2; pH 4.4). Mobile phase B consisted of methanol: 1-propanol (Labscan, Samutsakorn, Thailand): $1 M$ ammonium acetate (78:20:2; $\mathrm{pH} 4.4)$. The HPLC flow rate was $0.6 \mathrm{~mL} / \mathrm{min}$ and the gradient profile consisted of a 5 -min constant gradient at $0 \%$ mobile phase B, a 21-min linear gradient from 0 to $80 \%$ mobile phase B, a 10-min linear gradient from 80 to $100 \%$ mobile phase $\mathrm{B}$, and $14 \mathrm{~min}$ isocratic at $100 \%$ mobile phase $\mathrm{B}$ before returning to initial conditions in $5 \mathrm{~min}$. Cell potentials were set at 200, 400, 500, $700,800,-1,000,200$, and $500 \mathrm{mV}$ versus palladium reference. An ODS Hypersil 150 column $(3 \times 150 \mathrm{~mm}$; $3 \mu \mathrm{m}$; Thermo Scientific) was used and the system temperature was set at $37^{\circ} \mathrm{C}$.

\section{Statistical Analyses}

All biochemical data are presented as means \pm SEM. Linear mixed models were fitted to model the effect of the energy balance (EB) and bC supplementation on the serum and FF biochemical parameters (JMP Pro 11, SAS Institute Inc., Cary, NC). As fixed effects, we included the main effects of $\mathrm{EB}$ and $\mathrm{bC}$ supplementation as well as their interaction. If the interaction term was significant, the effect of supplementation (or of $\mathrm{EB}$ ) on the outcome parameter differed according to the status of the other fixed factor (EB or supplementation). In that case, separate effect sizes and significance levels were calculated for each fixed factor separately. If no significant interaction between EB and supplementation was present, main effect sizes for
EB and bC supplementation were calculated as well as their significance level. To account for the relatedness between observations within the same cow, a random intercept term for cow identification number was added to the model. Pairwise correlation between plasma and FF values were expressed using the Spearman correlation coefficient. Values of $P<0.05$ were considered significant.

\section{RESULTS}

Raw data are shown in Table 2 including $P$-values of the interaction term and main effects of $\mathrm{EB}$ and bC supplementation. Effect sizes are expressed in percentages and described below.

\section{Animals}

All 6 cows lost on average 11.5\% BW (65.88 \pm 4.04 $\mathrm{kg})$ during both NEB periods $(P<0.001)$, with initial $\mathrm{BW}$ at the beginning of NEB+bC $(564.75 \pm 27.62 \mathrm{~kg})$ and NEB-bC $(581.50 \pm 27.81 \mathrm{~kg})$ being comparable. All follicles punctured displayed an E2/P4 ratio $>1$ $(18.10 \pm 4.65$ on average), indicating the collection of FF of estrogen-dominated healthy follicles only.

\section{Vitamin Levels in Plasma and FF in Nonlactating NEB Cows}

$\boldsymbol{\beta}$-Carotene. The same profile of bC concentrations can be seen in plasma and FF, implying a significant correlation between plasma and FF bC levels ( $\rho=$ 0.645; Figure 2A), whereby FF bC concentrations were on average 10 times lower compared with plasma levels. Despite the nonsignificant interaction between EB and bC supplementation, the effect of EB was analyzed for the supplemented and nonsupplemented groups separately. The NEB significantly reduced follicular bC concentrations by $76.2 \%$ when cows were not supplemented with bC $(P<0.05)$. No significant effect of EB was observed in plasma. On the other hand, daily bC supplementation of 2,000 mg caused a significant rise in bC concentrations in both compartments. Plasma bC concentrations increased by $332.9 \%(P<0.001)$ following supplementation, whereas $\mathrm{FF}$ bC concentrations increased by $280.8 \%(P<0.001)$, independent of the energy status.

Retinol. In contrast to bC, plasma and FF retinol (vitamin A) concentrations were in the same range. Both retinol concentrations correlated significantly $(\rho$ $=0.715$; Figure 2B). Moreover, plasma retinol was correlated with bC in the blood as well $(\rho=0.678)$, but no significant correlation was found between FF retinol and FF bC $(\rho=0.194)$. 
BETA-CAROTENE IN FOLLICULAR FLUID OF DAIRY COWS

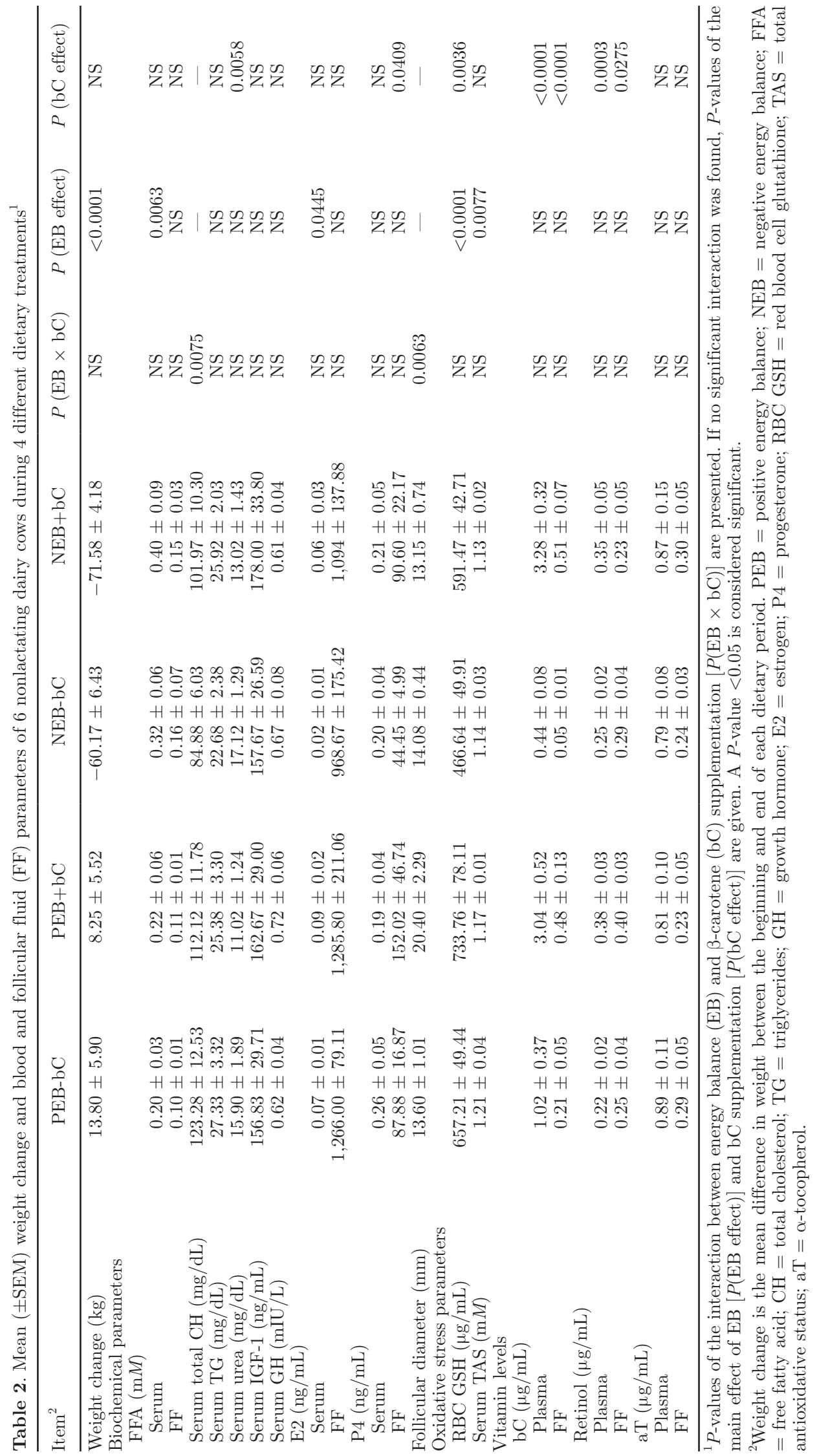


DE BIE ET AL.

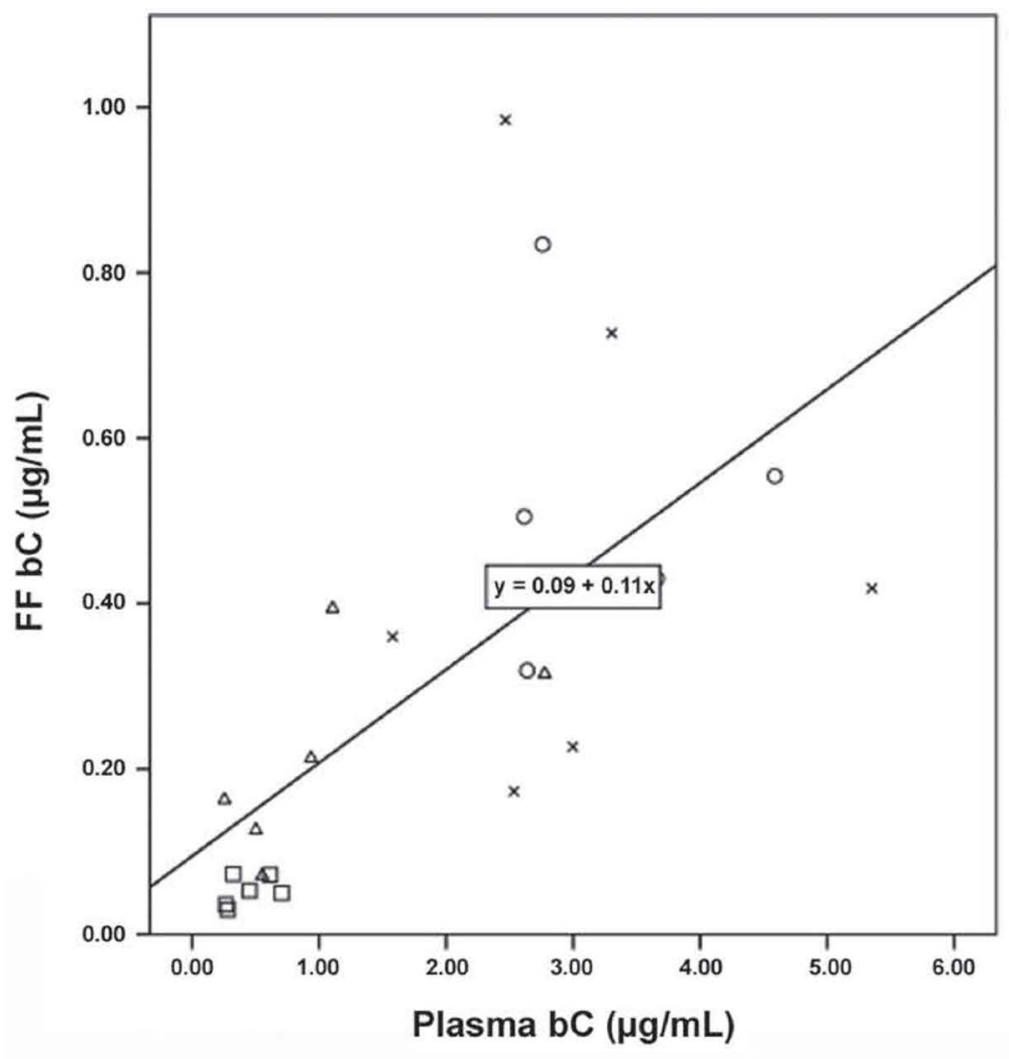

Treatment

ONEB+bC

$\square$ NEB-bC

$\times P E B+b C$

$\triangle \mathrm{PEB}-\mathrm{bC}$

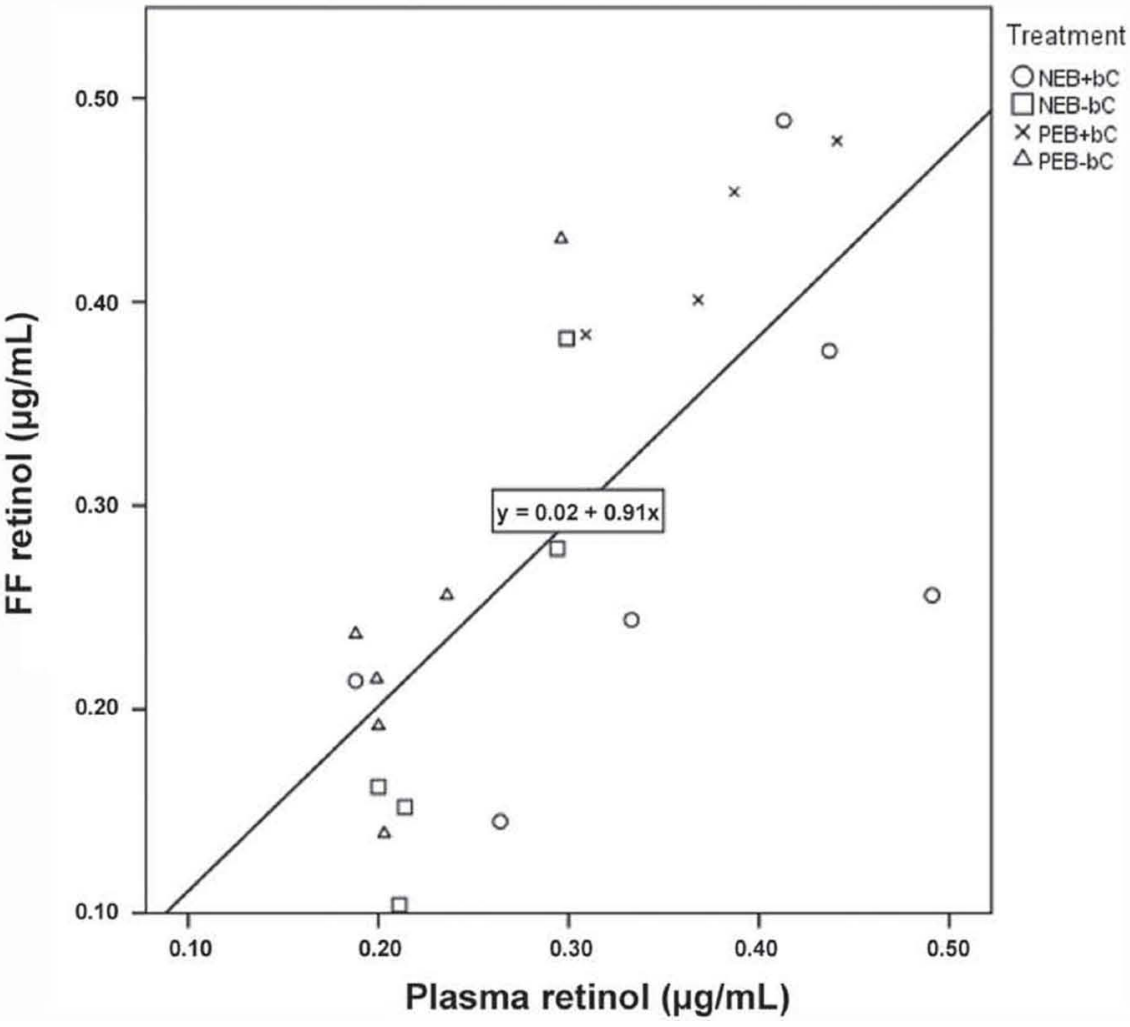

Figure 2. Graphic presentation of the significant correlations (Spearman rho, $\rho$ ) between (A) plasma and follicular fluid (FF) $\beta$-carotene (bC) concentrations $(\rho=0.645)$, and $(B)$ plasma and FF retinol $(\rho=0.715)$ concentrations. NEB $=$ negative energy balance; PEB $=$ positive energy balance. 
Plasma and FF retinol concentrations were similarly influenced by daily supplementation during NEB and PEB (no significant interaction $\mathrm{EB} \times \mathrm{bC}$ ). Both plasma and $\mathrm{FF}$ retinol levels increased after daily bC supplementation by $55.3 \%(P<0.001)$ and $16.7 \%(P<$ $0.05)$, respectively.

$\boldsymbol{\alpha}$-Tocopherol. Follicular aT concentrations were 3 to 4 times lower compared with plasma levels. No significant differences were found in plasma and $\mathrm{FF}$ aT concentrations with regard to the energy status or bC supplementation.

\section{Oxidative Stress Levels in Nonlactating NEB Cows}

$\beta$-Carotene supplementation raised GSH concentrations in RBC both in NEB and PEB in the same way (no significant interaction of $\mathrm{EB} \times \mathrm{bC}$ ). A reduction in DMI significantly reduced average RBC GSH concentrations by $23.9 \%(P<0.001)$ compared with PEB cows. Regardless of EB, daily bC supplementation significantly raised these RBC GSH levels by $17.9 \%(P<$ 0.01) compared with nonsupplemented cows. The total capacity to reduce oxidative agents in the blood (no significant interaction $\mathrm{EB} \times \mathrm{bC}$ ), measured by the TAS in serum, was significantly reduced in NEB with $4.6 \%$ $(P<0.01)$ compared with $\mathrm{PEB}$ cows, but could not be significantly altered by bC supplementation $(+\mathrm{bC}$ versus $-\mathrm{bC} ; P>0.05)$.

\section{Biochemical Parameters}

No significant interaction was found between EB and $\mathrm{bC}(\mathrm{EB} \times \mathrm{bC})$ regarding serum and FF FFA concentrations. As such, bC supplementation did not affect serum and FF FFA concentrations. A dietary induced NEB significantly increased serum FFA concentrations by $71.4 \%(P<0.01)$, but not follicular FFA concentrations, compared with PEB cows. Depending on the energy status, bC supplementation had a different effect on total serum $\mathrm{CH}$ (significant interaction $\mathrm{EB} \times \mathrm{bC}$ of $P<0.01)$. Total $\mathrm{CH}$ significantly decreased by $31.1 \%$ $(P<0.01)$ in NEB when not supplemented and by 9.1\% $(P<0.05)$ in NEB when supplemented with bC compared with $\mathrm{PEB}$ cows. Total CH levels significantly increased by $20.1 \%(P<0.05)$ in NEB when bC was supplemented compared with nonsupplemented NEB cows. No significant difference was found in total serum $\mathrm{CH}$ in $\mathrm{PEB}$ when supplemented with bC or not.

No significant effects of energy status or bC supplementation were found on serum TG, IGF-1, or GH concentrations. The bC supplementation significantly reduced serum urea concentrations by $27.2 \%(P<$ 0.01 ), independent of the energy status (no significant interaction of $\mathrm{EB} \times \mathrm{bC}$ ). No significant interaction be- tween EB and bC supplementation was found on serum and FF E2 and P4 concentrations. A reduction in DMI significantly reduced circulating serum E2 concentrations by $50.0 \%(P<0.05)$, but not $\mathrm{P} 4$ levels, when compared with PEB cows. Moreover, daily bC supplementation did increase follicular P4 concentrations 83.3\% $(P<0.05)$, but not E2 levels. Follicular diameters of the punctured dominant follicles depended on $\mathrm{EB}$ and supplementation (significant interaction of $\mathrm{EB}$ $\times$ bC). When not supplemented, follicular diameters were not significantly affected by EB. In contrast, when supplemented, NEB significantly reduced follicular diameters by $35.5 \%$ compared with PEB cows $(P<0.05)$. Whereas supplementation had no significant effect on follicular diameter in NEB, in PEB, follicular diameters were $50.0 \%$ larger with supplementation compared with diameters in nonsupplemented PEB cows $(P<0.05)$.

\section{DISCUSSION}

$\beta$-Carotene has been proposed as an important antioxidant in the metabolically stressed postpartum dairy cow. Its presence in the blood and FF is subject to a series of changes during this transition period such as the milk production level and NEB status of a cow. In this context, we showed, using a nonlactating dietary induced NEB cow model, that this NEB status was able to reduce follicular bC levels and other plasma antioxidative parameters such as TAS and RBC GSH, but not plasma bC and retinol concentrations in supplemented and nonsupplemented cows. However, after daily bC supplemention, bC and retinol concentrations drastically increased in both blood and $\mathrm{FF}$ compartments and RBC GSH levels could be restored to levels present in healthy PEB cows. Additionally, follicular diameter increased in PEB cows after supplementation with bC.

Evidence exists (Michal et al., 1994; Chawla and Kaur, 2004; Calderón et al., 2007) that plasma bC concentrations significantly decrease during the periparturient period in high-producing dairy cows. In our dietary induced NEB model, we observed a higher increase in plasma and FF bC in NEB when supplemented (8- to 10-fold increase) compared with the increase seen after supplementation in PEB cows (2- to 3 -fold increase). Regardless of the significant reduction in follicular $\mathrm{bC}$, we could not substantiate this negative effect in plasma bC in our undernutritioned NEB cow model. It is important to mention that, compared with the NEB status in the present study, the periparturient metabolic state in lactating dairy cows is more complex and $\mathrm{bC}$ can be reduced due to several factors: (1) loss of bC in colostrum and milk (Calderón et al., 2007; Kankofer and Albera, 2008), (2) low-quality forages during the dry period with lower bC concentrations in the diet 
(Calderón et al., 2007), (3) health problems such as liver steatosis (resulting in disturbed bC redistribution and metabolism; Jorritsma et al., 2004), and (4) even higher systemic OS levels (Bernabucci et al., 2005; Pedernera et al., 2010). Furthermore, periparturient dairy cows have a reduced DMI and thus less bC uptake from the ration. This is an important factor that was not taken into consideration in our controlled experimental set-up because the amount of bC supplement was fixed throughout NEB and PEB treatment periods. Despite this discordance, but free of many important confounders seen in similar studies in lactating cows, our data emphasize the possibility of bC supplementation to substantially increase bC levels in plasma and $\mathrm{FF}$ in undernutritioned cows.

$\beta$-Carotene was supplemented in a dosage exceeding daily recommendations (Calsamiglia and Rodríguez, 2012), but matching the amount of total bC intake at grazing (Kawashima et al., 2010). After dietary intake, $\mathrm{bC}$ will be absorbed in the intestines where it can partly be metabolized to retinol (vitamin A). In the liver, bC present in chylomicrons can be metabolized or temporally stored (Yang et al., 1992). Stored bC will be released in the blood circulation as lipoproteins, of which the high-density lipoproteins (HDL) are the major transporter for bC in the blood, with large HDL containing more bC than small-sized HDL (Ashes et al., 1984; Schweigert et al., 1987). The basal membrane of the blood-follicle barrier allows only the passage of small HDL, explaining the observed lower follicular bC concentrations compared with plasma (Perret et al., 1985; Zamah et al., 2009). Additionally, granulosa cells of the follicular wall can actively take up and convert $\mathrm{bC}$ to its nonantioxidant metabolite retinol (Schweigert et al., 1988; Schweigert and Zucker, 1988; Brown et al., 2003). This explains the lower follicular bC concentrations compared with plasma and might contribute to the observed high intra-follicular retinol concentrations (in contrast to bC, follicular retinol levels were very much like plasma levels). This can also be a result of a different transport mechanism of retinol (retinol binding proteins), compared with bC (Noy, 2000), and may also indicate why no correlation was found between bC and retinol in the follicle. If not selectively taken up by follicle cells, retinol passively diffuses into FF (Ikeda et al., 2005). The average physiological plasma bC and retinol concentrations are in line with previous reports of plasma bC and retinol levels in dairy cows (Chew et al., 1984; Haliloglu et al., 2002; LeBlanc et al., 2004), but bC levels are deficient based on current guidelines. Hence, it would be recommended to supplement these cows with bC (Schweigert and Immig, 2007; Calsamiglia and Rodríguez, 2012).
Bernabucci et al. (2005) showed that a severe decrease in body condition in periparturient cows is associated with higher levels of OS. This relation between energy status and systemic OS was indicated in our study by the significant lower erythrocyte levels of GSH and TAS in NEB compared with PEB cows. Furthermore, daily bC supplementation could alleviate these high OS levels in NEB cows by significantly increasing RBC GSH concentrations, but not TAS, to PEB levels again. Care needs to be taken when interpreting TAS as a proxy for the cow's OS status, because it only shows a general image. Depletion of one antioxidant can be masked by the rise of another antioxidant or a higher production of overall reactive oxygen species can be counteracted by the subsequent elevated action of naturally present antioxidants (Hermans et al., 2007).

Reports on the effect of nutrient restriction and NEB in dairy cows on follicular diameter are contradictory (Lucy et al., 1991; Mackey et al., 1999; Comin et al., 2002; Diskin et al., 2003). Most researchers report a restricted follicular growth during a period of reduced dietary intake, which could not be confirmed in our experiment. In contrast, we observed an increased follicular diameter in supplemented PEB animals compared with supplemented NEB and nonsupplemented PEB cows. Except for the findings of Kawashima et al. (2009), who described a positive relation between the start of postpartum ovarian activity in cows with higher circulating bC levels, evidence is lacking of a direct influence of bC on follicular growth. The finding of Schweigert and Zucker (1988) is noteworthy, showing that follicular retinol concentrations are higher in large good quality follicles, whereas follicular bC is not influenced by follicle size or quality, emphasizing the importance of retinol in follicle development. Retinol has been identified as a growth-promoting factor (Goldblith and Joslyn, 1964). As such, we assume that the significant higher retinol levels in FF after daily bC supplementation can stimulate follicular growth through granulosa cell proliferation (Schweigert and Zucker, 1988).

Follicular fluid of growing dominant pre-ovulatory follicles was sampled, which was supported by the much higher follicular E2 concentrations than P4 levels at the moment of FF sampling. The significant negative effect of dietary restriction, and thus NEB, on circulating E2 levels confirmed the findings of Kendrick et al. (1999) and Comin et al. (2002). Evidence exists that antioxidant vitamins, such as bC, support steroid synthesis (Young et al., 1995; Haliloglu et al., 2002; Arellano-Rodriguez et al., 2009). Besides bC, retinol might have a steroidogenic effect as well because it has been shown that vitamin A deficiency is characterized by a reduced steroid hormone production (Ganguly et 
al., 1971). In line with this, follicular P4 significantly increased with daily bC supplementation. Young et al. (1995) previously showed that bC has an antioxidant protective effect on the cholesterol side-chain cleavage enzyme cytochrome $\mathrm{P} 450$, stimulating the production of pregnenolone, a direct precursor of $\mathrm{P} 4$. Moreover, $\mathrm{P} 4$ plays a pivotal role in follicle dominance, oocyte ovulation, and oocyte developmental competence (for review see Fair and Lonergan, 2012). Additionally, based on previous in vitro research (Ikeda et al., 2005; Shelly et al., 2008; Rooke et al., 2012) and the evidence that $\mathrm{bC}$ levels in the micro-environment of the oocyte can substantially rise regardless of the energy status of the cow, we can now speculate that these follicular bC can alleviate FFA-induced OS in follicle cells and oocytes.

In conclusion, a dietary induced NEB lowers follicular bC concentrations and increases systemic OS levels, but does not negatively alter plasma bC and plasma and follicular retinol levels. However, daily supplementation with 2,000 $\mathrm{mg}$ of bC can significantly increase $\mathrm{bC}$ and retinol concentrations in the environment of the oocyte, regardless of the energy status of the cow. Consequently, bC can exert its antioxidative effects in the $\mathrm{FF}$, whereas retinol may favor follicular development. These findings stress the potential of bC supplementation to positively alter the micro-environment of the oocyte, which may have a positive influence on oocyte quality in the presence of maternal metabolic stress. This can be taken into account when planning future in vivo and in vitro experiments to investigate direct effects of bC on metabolically compromised oocytes. This study is a first important step in designing management strategies to feed for optimal oocyte quality, in an attempt to tackle the subfertility problem in the modern dairy industry.

\section{ACKNOWLEDGMENTS}

The authors thank Lies Jordaens, Veerle Van Hoeck, Sara Valckx, Karolien Desmet, Els Merckx, Silke Andries, and Gilbert Van den Plas for their help in animal care and veterinary assistance throughout the research trial. In addition, thanks to the Algemeen Medisch Laboratorium (Antwerp, Belgium) for biochemical analyses of blood and follicular fluid samples. This study was funded by the Flemish Research Fund (FWO grant, G019214N) and the Special Research Fund (BOF-UA, 28115).

\section{REFERENCES}

Akar, Y., and A. Gazioglu. 2006. Relationship between vitamin A and beta-carotene levels during the postpartum period and fertility parameters in cows with and without retained placenta. Bull Vet. Inst. Pulawy 50:93-96.
Aréchiga, C. F., S. Vazquez-Flores, O. Ortiz, J. Hernandez-Ceron, A. Porras, L. R. McDowell, and P. J. Hansen. 1998. Effect of injection of beta-carotene or vitamin $\mathrm{E}$ and selenium on fertility of lactating dairy cows. Theriogenology 50:65-76.

Arellano-Rodriguez, G., C. A. Meza-Herrera, R. Rodriguez-Martinez, R. Dionisio-Tapia, D. M. Hallford, M. Mellado, and A. GonzalezBulnes. 2009. Short-term intake of beta-carotene-supplemented diets enhances ovarian function and progesterone synthesis in goats. J. Anim. Physiol. Anim. Nutr. (Berl.) 93:710-715.

Ashes, J. R., R. W. Burley, G. S. Sidhu, and R. W. Sleigh. 1984. Effect of particle-size and lipid-composition of bovine blood high-density lipoprotein on its function as a carrier of beta-carotene. Biochim. Biophys. Acta 797:171-177.

Barroeta, A. C., M. D. Baucells, A. Blanco Pérez, S. Calsamiglia, R. Casals, R. Cepero Briz, R. Davin, G. Gonzalez, J. M. Hernandez, B. Isabel, C. Lopez Bote, I. A. Rey, M. Rodriguez, J. Sanz, M. F. Soto-Salanova, and G. Weber. 2012. Optimum vitamin nutrition in the production of quality animal foods. 5M Publishing, Sheffield, UK.

Beam, S. W., and W. R. Butler. 1997. Energy balance and ovarian follicle development prior to the first ovulation postpartum in dairy cows receiving three levels of dietary fat. Biol. Reprod. 56:133-142.

Bernabucci, U., B. Ronchi, N. Lacetera, and A. Nardone. 2005. Influence of body condition score on relationships between metabolic status and oxidative stress in periparturient dairy cows. J. Dairy Sci. 88:2017-2026.

Blomhoff, R., M. H. Green, J. B. Green, T. Berg, and K. R. Norum. 1991. Vitamin-A metabolism-New perspectives on absorption, transport, and storage. Physiol. Rev. 71:951-990.

Bols, P. E. J., J. M. M. Vandenheede, A. Vansoom, and A. Dekruif. 1995. Transvaginal ovum pick-up (OPU) in the cow-A new disposable needle guidance-system. Theriogenology 43:677-687.

Bremel, D. H., R. W. Hemken, G. J. Heersche, L. A. Edgerton, and D. Olds. 1982. Effects of $\beta$-carotene on metabolic and reproductive parameters in lactating dairy cows. J. Dairy Sci. 65(Suppl. 1):178.

Brown, J. A., D. M. Eberhardt, F. N. Schrick, M. P. Roberts, and J. D. Godkin. 2003. Expression of retinol-binding protein and cellular retinol-binding protein in the bovine ovary. Mol. Reprod. Dev. 64:261-269.

Butler, W. R. 2003. Energy balance relationships with follicular development, ovulation and fertility in postpartum dairy cows. Livest. Prod. Sci. 83:211-218.

Calderón, F., B. Chauveau-Duriot, B. Martin, B. Graulet, M. Doreau, and P. Noziere. 2007. Variations in carotenoids, vitamins A and E, and color in cow's plasma and milk during late pregnancy and the first three months of lactation. J. Dairy Sci. 90:2335-2346.

Calsamiglia, S., and M. Rodríguez. 2012. Optimum vitamin nutrition in dairy cattle. Pages 335-373 in Optimum Vitamin Nutrition. DSM Nutritional Products Ltd., Basel, Switzerland.

Chagas, L. M., J. J. Bass, D. Blache, C. R. Burke, J. K. Kay, D. R. Lindsay, M. C. Lucy, G. B. Martin, S. Meier, F. M. Rhodes, J. R. Roche, W. W. Thatcher, and R. Webb. 2007. Invited review: New perspectives on the roles of nutrition and metabolic priorities in the subfertility of high-producing dairy cows. J. Dairy Sci. 90:4022-4032.

Chaveau-Duriot, B., D. Thomas, J. Portelli, and M. Doreau. 2005. Carotenoids content in forages: Variation during conservation. Renc Rech Ruminants 12:117.

Chawla, R., and H. Kaur. 2004. Plasma antioxidant vitamin status of periparturient cows supplemented with alpha-tocopherol and betacarotene. Anim. Feed Sci. Technol. 114:279-285.

Chew, B. P., D. M. Holpuch, and J. V. O'Fallon. 1984. Vitamin A and beta-carotene in bovine and porcine plasma, liver, corpora lutea, and follicular fluid. J. Dairy Sci. 67:1316-1322.

Comin, A., D. Gerin, A. Cappa, V. Marchi, R. Renaville, M. Motta, U. Fazzini, and A. Prandi. 2002. The effect of an acute energy deficit on the hormone profile of dominant follicles in dairy cows. Theriogenology 58:899-910.

CRV. 2012. CRV Statistics. Published September 2013.

de Ondarza, M. B. and M. Engstrom. 2009. Can beta-carotene help dairy reproduction? Feedstuffs 81:40. 
Dimitrov, N. V., C. W. Boone, and M. B. Hay. 1986. Plasma betacarotene levels-kinetic patterns during administration of various doses of beta-carotene. J. Nutr. Growth Cancer 3:227-237.

Diskin, M. G., D. R. Mackey, J. F. Roche, and J. M. Sreenan. 2003. Effects of nutrition and metabolic status on circulating hormones and ovarian follicle development in cattle. Anim. Reprod. Sci. $78: 345-370$.

Drackley, J. K., H. M. Dann, G. N. Douglas, N. A. J. Guretzky, N. B. Litherland, J. P. Underwood, and J. J. Loor. 2005. Physiological and pathological adaptations in dairy cows that may increase susceptibility to periparturient diseases and disorders. Ital. J. Anim. Sci. 4:323-344.

Drackley, J. K., T. R. Overton, and G. N. Douglas. 2001. Adaptations of glucose and long-chain fatty acid metabolism in liver of dairy cows during the periparturient period. J. Dairy Sci. 84(Suppl):E100-E112.

Dupont, J., R. J. Scaramuzzi, and M. Reverchon. 2014. The effect of nutrition and metabolic status on the development of follicles, oocytes and embryos in ruminants. Animal 8:1031-1044.

Fair, T., and P. Lonergan. 2012. The role of progesterone in oocyte acquisition of developmental competence. Zuchthygiene 47(Suppl. 4):142-147.

Folman, Y., M. Rosenberg, I. Ascarelli, M. Kaim, and Z. Herz. 1983. The effect of dietary and climatic factors on fertility, and on plasma progesterone and oestradiol-17-beta levels in dairy cows. J. Steroid Biochem. 19:863-868.

Ganguly, J., H. B. Waynforth, G. S. Pope, S. Y. Thompson, J. Toothill, and J. D. Edwards-Webb. 1971. Studies on the metabolism of vitamin A: The effect of vitamin A status on the content of some steroids in the ovaries of pregnant rats. Biochem. J. 123:669-670.

Goldblith, S. A., and M. A. Joslyn. 1964. Milestones in Nutrition. AVI Publ. Co., Westport, CT.

Gossen, N., and M. Hoedemaker. 2005. Effect of beta-carotene serum concentration on the reproductive performance in dairy cows. Berl. Munch. Tierarztl. Wochenschr. 118:326-333.

Haliloglu, S., N. Baspinar, B. Serpek, H. Erdem, and Z. Bulut. 2002 Vitamin A and beta-carotene levels in plasma, corpus luteum and follicular fluid of cyclic and pregnant cattle. Zuchthygiene 37:9699.

Hermans, N., P. Cos, D. V. Berghe, A. J. Vlietinck, and T. de Bruyne. 2005. Method development and validation for monitoring in vivo oxidative stress: Evaluation of lipid peroxidation and fat-soluble vitamin status by HPLC in rat plasma. J. Chromatogr. B Analyt. Technol. Biomed. Life Sci. 822:33-39.

Hermans, N., P. Cos, L. Maes, T. De Bruyne, D. Vanden Berghe, A. J. Vlietinck, and L. Pieters. 2007. Challenges and pitfalls in antioxidant research. Curr. Med. Chem. 14:417-430.

Ikeda, S., M. Kitagawa, H. Imai, and M. Yamada. 2005. The roles of vitamin A for cytoplasmic maturation of bovine oocytes. J. Reprod. Dev. 51:23-35.

Iwańska, S., and D. Strusinska. 1997. The effect of beta-carotene and vitamins A, D-3 and E on some reproductive parameters in cows. Acta Vet. Hung. 45:95-107.

Jorritsma, R., A. Murondoti, P. L. Vos, J. P. Noordhuizen, T. A. Kruip, and T. Wensing. 2004. Metabolic homeostasis in postpartum dairy cows hampered by fatty livers. Vet. Rec. 155:151-152.

Kankofer, M., and E. Albera. 2008. Postpartum relationship of beta carotene and vitamin A between placenta, blood and colostrum in cows and their newborns. Exp. Clin. Endocrinol. Diabetes 116:409-412.

Kawashima, C., K. Kida, F. J. Schweigert, and A. Miyamoto. 2009. Relationship between plasma beta-carotene concentrations during the peripartum period and ovulation in the first follicular wave postpartum in dairy cows. Anim. Reprod. Sci. 111:105-111.

Kawashima, C., S. Nagashima, K. Sawada, F. J. Schweigert, A. Miyamoto, and K. Kida. 2010. Effect of $\beta$-carotene supply during close-up dry period on the onset of first postpartum luteal activity in dairy cows. Zuchthygiene 45:e282-e287.

Kendrick, K. W., T. L. Bailey, A. S. Garst, A. W. Pryor, A. Ahmadzadeh, R. M. Akers, W. E. Eyestone, R. E. Pearson, and F. C. Gwazdauskas. 1999. Effects of energy balance on hormones, ovarian activity, and recovered oocytes in lactating Holstein cows using transvaginal follicular aspiration. J. Dairy Sci. 82:1731-1741.

LeBlanc, S. 2010. Does higher production imply worse reproduction? Pages 253-263 in Advances in Dairy Technology, Western Canadian Dairy Seminar. Vol. 22. L. Doepel, ed. University of Alberta, Dept. Agr. Food \& Nutr. Sci., Edmonton, Canada.

LeBlanc, S. J., T. H. Herdt, W. M. Seymour, T. F. Duffield, and K. E. Leslie. 2004. Peripartum serum vitamin E, retinol, and beta-carotene in dairy cattle and their associations with disease. J. Dairy Sci. 87:609-619.

Leroy, J. L., R. G. Sturmey, V. Van Hoeck, J. De Bie, P. J. McKeegan, and P. E. Bols. 2014. Dietary fat supplementation and the consequences for oocyte and embryo quality: Hype or significant benefit for dairy cow reproduction? Zuchthygiene 49:353-361.

Leroy, J. L., T. Vanholder, J. R. Delanghe, G. Opsomer, A. Van Soom, P. E. Bols, and A. de Kruif. 2004a. Metabolite and ionic composition of follicular fluid from different-sized follicles and their relationship to serum concentrations in dairy cows. Anim. Reprod. Sci. 80:201-211

Leroy, J. L., T. Vanholder, J. R. Delanghe, G. Opsomer, A. Van Soom, P. E. Bols, J. Dewulf, and A. de Kruif. 2004b. Metabolic changes in follicular fluid of the dominant follicle in high-yielding dairy cows early post partum. Theriogenology 62:1131-1143.

Leroy, J. L., T. Vanholder, B. Mateusen, A. Christophe, G. Opsomer, A. de Kruif, G. Genicot, and A. Van Soom. 2005. Non-esterified fatty acids in follicular fluid of dairy cows and their effect on developmental capacity of bovine oocytes in vitro. Reproduction 130:485-495.

Leroy, J. L. M. R., D. Rizos, R. Sturmey, P. Bossaert, A. GutierrezAdan, V. Van Hoeck, S. Valckx, and P. E. J. Bols. 2011. Intrafollicular conditions as a major link between maternal metabolism and oocyte quality: A focus on dairy cow fertility. Reprod. Fertil. Dev. 24:1-12.

Lin, C., J. M. Yon, A. Y. Jung, J. G. Lee, K. Y. Jung, B. J. Lee, Y. W. Yun, and S. Y. Nam. 2013. Antiteratogenic effects of betacarotene in cultured mouse embryos exposed to nicotine. Evid. Based Complement. Altern. Med. 2013:575287.

Lucy, M. C., C. R. Staples, F. M. Michel, and W. W. Thatcher. 1991. Energy balance and size and number of ovarian follicles detected by ultrasonography in early postpartum dairy cows. J. Dairy Sci. $74: 473-482$

Mackey, D. R., J. M. Sreenan, J. F. Roche, and M. G. Diskin. 1999. Effect of acute nutritional restriction on incidence of anovulation and periovulatory estradiol and gonadotropin concentrations in beef heifers. Biol. Reprod. 61:1601-1607.

Michal, J. J., L. R. Heirman, T. S. Wong, B. P. Chew, M. Frigg, and L. Volker. 1994. Modulatory effects of dietary beta-carotene on blood and mammary leukocyte function in periparturient dairy cows. J. Dairy Sci. 77:1408-1421.

Natarajan, R., M. B. Shankar, and D. Munuswamy. 2010. Effect of alpha-tocopherol supplementation on in vitro maturation of sheep oocytes and in vitro development of preimplantation sheep embryos to the blastocyst stage. J. Assist. Reprod. Genet. 27:483-490.

Noy, N. 2000. Retinoid-binding proteins: Mediators of retinoid action. Biochem. J. 348:481-495.

Olson, S. E., and G. E. Seidel. 2000. Culture of in vitro-produced bovine embryos with vitamin $\mathrm{E}$ improves development in vitro and after transfer to recipients. Biol. Reprod. 62:248-252.

Pascoe, G. A., M. W. Fariss, K. Olafsdottir, and D. J. Reed. 1987. A role of vitamin $\mathrm{E}$ in protection against cell injury. Eur. J. Biochem. 166:241-247.

Pedernera, M., P. Celi, S. C. Garcia, H. E. Salvin, I. Barchia, and W. J. Fulkerson. 2010. Effect of diet, energy balance and milk production on oxidative stress in early-lactating dairy cows grazing pasture. Vet. J. 186:352-357.

Perret, B. P., J. Parinaud, H. Ribbes, J. P. Moatti, G. Pontonnier, H. Chap, and L. Douste-Blazy. 1985. Lipoprotein and phospholipid distribution in human follicular fluids. Fertil. Steril. 43:405-409.

Premkumar, B. J., and A. Agarwal. 2012. Female infertility and assisted reproduction: impact of oxidative stress-an update. Curr. Womens Health Rev. 8:183-207. 
Rooke, J. A., R. G. Watt, C. J. Ashworth, and T. G. McEvoy. 2012. Inclusion of bovine lipoproteins and the vitamin $\mathrm{E}$ analogue, Trolox, during in vitro culture of bovine embryos changes both embryo and fetal development. Reprod. Fertil. Dev. 24:309-316.

Rukkwamsuk, T., T. Wensing, and T. A. M. Kruip. 1999. Relationship between triacylglycerol concentration in the liver and first ovulation in postpartum dairy cows. Theriogenology 51:1133-1142.

Sangsritavong, S., D. K. Combs, R. Sartori, L. E. Armentano, and M. C. Wiltbank. 2002. High feed intake increases liver blood flow and metabolism of progesterone and estradiol-17 $\beta$ in dairy cattle. J. Dairy Sci. 85:2831-2842.

Santos, J. E. P., R. S. Bisinotto, E. S. Ribeiro, F. S. Lima, L. F. Greco, C. R. Staples, and W. W. Thatcher. 2010. Applying nutrition and physiology to improve reproduction in dairy cattle. Pages 387-403 in Reproduction in Domestic Ruminants VII. Vol. 67. M. C. Lucy, J. L. Pate, M. F. Smith, and T. E. Spencer, ed. Nottingham University Press, Loughborough, UK.

Schwedhelm, E., R. Maas, R. Troost, and R. H. Boger. 2003. Clinical pharmacokinetics of antioxidants and their impact on systemic oxidative stress. Clin. Pharmacokinet. 42:437-459.

Schweigert, F. J., and I. Immig. 2007. Rapid assessment of beta-carotene status. Int. Dairy Topics 6:15-17.

Schweigert, F. J., W. A. Rambeck, and H. Zucker. 1987. Transport of beta-carotene by the serum-lipoproteins in cattle. J. Anim. Physiol. Anim. Nutr. (Berl.) 57:162-167.

Schweigert, F. J., M. Wierich, W. A. Rambeck, and H. Zucker. 1988. Carotene cleavage activity in bovine ovarian follicles. Theriogenology 30:923-930.

Schweigert, F. J., and H. Zucker. 1988. Concentrations of vitamin A, beta-carotene and vitamin $\mathrm{E}$ in individual bovine follicles of different quality. J. Reprod. Fertil. 82:575-579.

Shelly, W. B., R. W. Browne, H. G. Huddleston, J. R. Sandler, and V. Y. Fujimoto. 2008. Beta-carotene levels in follicular fluid correlate with successful in vitro fertilization of human oocytes. Reprod. Sci. 15:171a.

Tao, Y., H. Chen, N. N. Tian, D. T. Huo, G. Li, Y. H. Zhang, Y. Liu, F. G. Fang, J. P. Ding, and X. R. Zhang. 2010. Effects of L-ascorbic acid, alpha-tocopherol and co-culture on in vitro developmental potential of porcine cumulus cells free oocytes. Zuchthygiene 45:19-25.

Van Hoeck, V., J. De Bie, S. Andries, E. Merckx, P. E. J. Bols, and J. L. M. R. Leroy. 2012. Elevated concentrations of saturated NEFA during bovine in vitro embryo culture compromise pre-implantation embryo development. Page 224 in Proc. 28th Scientific Meeting AETE, St-Malo, France.

Van Hoeck, V., J. L. M. R. Leroy, M. Arias-Alvarez, D. Rizos, A. Gutierrez-Adan, K. Schnorbusch, P. E. J. Bols, H. J. Leese, and R. G. Sturmey. 2013. Oocyte developmental failure in response to elevated non-esterified fatty acid concentrations: Mechanistic insights. Reproduction 145:33-44.

Van Hoeck, V., R. G. Sturmey, P. Bermejo-Alvarez, D. Rizos, A. Gutierrez-Adan, H. J. Leese, P. E. Bols, and J. L. Leroy. 2011. Elevated non-esterified fatty acid concentrations during bovine oocyte maturation compromise early embryo physiology. PLoS ONE $6: \mathrm{e} 23183$

Vanholder, T., J. L. Leroy, A. V. Soom, G. Opsomer, D. Maes, M. Coryn, and A. de Kruif. 2005. Effect of non-esterified fatty acids on bovine granulosa cell steroidogenesis and proliferation in vitro. Anim. Reprod. Sci. 87:33-44.

Warner, R. L., G. E. Mitchell Jr., C. O. Little, and N. E. Alderson. 1970. Pré-intestinal disappearance of vitamin A in steers fed different levels of corn. Int. Z Vitaminforsch 40:585-588.

Wathes, D. C., V. J. Taylor, Z. Cheng, and G. E. Mann. 2003. Follicle growth, corpus luteum function and their effects on embryo development in postpartum dairy cows. Reprod. Suppl. 61:219-237.

Yang, A., T. W. Larsen, and R. K. Tume. 1992. Carotenoid and retinol concentrations in serum, adipose-tissue and liver and carotenoid transport in sheep, goats and cattle. Aust. J. Agric. Res. 43:1809-1817.

Yeum, K. J., A. L. dos Anjos Ferreira, D. Smith, N. I. Krinsky, and R. M. Russell. 2000. The effect of alpha-tocopherol on the oxidative cleavage of beta-carotene. Free Radic. Biol. Med. 29:105-114.

Young, F. M., W. B. Luderer, and R. J. Rodgers. 1995. The antioxidant beta-carotene prevents covalent cross-linking between cholesterol side-chain cleavage cytochrome P450 and its electron donor, adrenodoxin, in bovine luteal cells. Mol. Cell. Endocrinol. 109:113-118.

Zamah, A. M., R. W. Browne, G. Conti, S. R. Jaggavarapu, V. Sridhar, and V. Y. Fujimoto. 2009. High density lipoprotein (HDL) particle size and composition predicts embryo fragmentation. Fertil. Steril. 92:S96-S97. 